Article

\title{
Realising Operational Energy Performance in Non-Domestic Buildings: Lessons Learnt from Initiatives Applied in Cambridge
}

\author{
Ray Pritchard 1,2,* (D) and Scott Kelly ${ }^{3,4}$ \\ 1 Department of Architecture and Planning, Faculty of Architecture and Design, \\ NTNU-Norwegian University of Science and Technology, 7491 Trondheim, Norway \\ 2 Centre for Sustainable Development, Department of Engineering, University of Cambridge, \\ Cambridge CB2 1PZ, UK \\ 3 Institute for Sustainable Futures, University of Technology, Sydney, NSW 2007, Australia; \\ Scott.Kelly@uts.edu.au \\ 4 Cambridge Centre for Climate Change Mitigation Research (4CMR), Department of Land Economy, \\ University of Cambridge, Cambridge CB3 9EP, UK \\ * Correspondence: raymond.pritchard@ntnu.no
}

Received: 8 May 2017; Accepted: 25 July 2017; Published: 1 August 2017

\begin{abstract}
The gap between the intended and actual energy performance of buildings is increasingly well documented in the non-domestic building sector. Recognition of this issue has led to the availability of a large range of initiatives that seek to ensure energy efficient building operation. This article reviews the practical implementation of three such initiatives in a case study building at the University of Cambridge. The notionally high-performance office/laboratory building implemented two voluntary design frameworks during building planning and construction: the voluntary rating scheme BREEAM and a bespoke Soft Landings framework called the Cambridge Work Plan. The building additionally meets the energy reporting criteria for the EU Energy Performance of Buildings Directive (EPBD), a legislative requirement for many publicly owned buildings in the UK. The relative impact of these three approaches for optimising building energy performance is reviewed through a mixed methods approach of building occupant and operator interviews, document analysis and energy performance review. The building's core functions were revealed to consume $140 \%$ more energy than the building logbook estimate for the same needs. This difference, referred to widely as the energy performance gap, is larger than the majority of reported UK university buildings in the energy reporting database CarbonBuzz. The three implemented initiatives are demonstrated to be inadequate for reducing the energy performance gap in the case study, thus a number of alternative energy efficiency approaches are additionally reviewed. Common to the three approaches used in the case study is a lack of verification of actual building performance despite ambitious sustainability targets, due to a heavy focus on the design-stage and few follow-up mechanisms. The paper demonstrates the potential of energy efficiency initiatives that are focussed on operational performance as a core criterion (such as the Living Building Challenge) together with those that ensure the creation of realistic energy estimates at the design stage (such as the Chartered Institution of Building Services Engineers (CIBSE) Technical Memorandum 54).
\end{abstract}

Keywords: building energy performance; energy performance gap; Soft Landings; BREEAM; EPBD; energy efficiency; green building rating; non-domestic buildings 


\section{Introduction}

Energy and climate targets in the UK require most sectors of the economy to make substantial improvements in energy efficiency to meet the legislated $80 \%$ cut in greenhouse gas emissions target by 2050 [1]. New buildings in particular have been given lofty energy performance targets under the EU Energy Performance of Buildings Directive (EPBD) whereby member states shall ensure that by 2020 all new buildings are nearly zero-energy buildings [2]. This legislation together with demand from building developers for assessment and recognition of improved building performance has meant that the building sector is already making significant progress. However, the environmental assessment of buildings is very often completed prior to handover (and thus without operational verification), and increasing evidence points to the underperformance of buildings in energy efficiency terms [3]. In recognition of the need to improve the operational energy performance of buildings, there has been a multitude of different standards, certification schemes, guidelines and legislation produced. This article reviews the effectiveness of three such methodologies implemented at the Institute for Manufacturing building (IfM) at the University of Cambridge. The case study building procurement process was examined closely to observe the extent to which the methodologies are implemented as intended, their potential contribution to energy performance and their appropriateness in the context of a broad field of competing methodologies available to building designers.

Building performance evaluations in the public domain have tended to focus on buildings that were heralded as exemplars of energy efficiency and/or sustainability [4,5] at the time of design or completion. Research on such buildings in the UK reveals that actual energy consumption is often double and sometimes as high as five times the initial design predictions [3-5]. More recent research in this field has covered a wider range of building types and design objectives, conducted under industry-focused collaborative funding arrangements $[3,6]$. One such example is the online energy reporting database CarbonBuzz, which for British university buildings reveals a particularly pronounced difference between mean predicted $\left(110 \mathrm{kWh} / \mathrm{m}^{2}\right.$ per annum) and actual energy consumption $\left(234 \mathrm{kWh} / \mathrm{m}^{2}\right.$ per annum) [7]. Such research has led to the popularisation of what is termed the energy performance gap to describe differences between design predictions and end-use measurements. Forman et al. have created a summary of the factors influencing the formation of performance gap, building also upon a university building context [8]. Comparing the energy performance gap of buildings is made difficult due to the incomplete scope of energy loads when using European regulatory compliance procedures. Similarly, there is no well defined sampling point for operational energy consumption, meaning that early energy consumption figures may not be indicative of longer term stable operation. Hours of operation can also be notional.

For notionally high performance buildings such as the IfM, the Post Occupancy Review of Buildings and their Engineering (PROBE) studies in the 1990s are an appropriate starting point to compare energy consumption patterns [9]. One review of PROBE's 23 case study buildings suggested "that actual energy consumption in buildings will usually be twice as much as predicted" [10]. More recently, Innovate UK has released the results for 50 selected non-domestic buildings, as part of its Building Performance Evaluation programme, revealing that average actual building $\mathrm{CO}_{2}$ emissions were 3.8 times greater than design predictions (which are required by the UK Building Regulations) [6].

This paper seeks to evaluate the energy performance of the IfM building by following the building procurement process from design and construction to operation and aftercare. In particular, the energy performance impact of three processes that were implemented during the building's development and operation are reviewed: Building Research Establishment Environment Assessment Method (BREEAM), Soft Landings Cambridge Work Plan and Part L of the Building Regulations in the UK (BRUKL), which implements the EU Energy Performance of Buildings Directive (EPBD). The paper is the first to the authors' knowledge which reviews the implementation of Soft Landings (in an early form prior to its public release). 


\section{Methodology}

This paper takes a mixed methods approach centred on a case study building in reviewing energy-performance attributes of BREEAM, the Cambridge Work Plan and BRUKL. Interviews were performed with the client, occupants and operators of the IfM building. In addition document analysis was used to extract findings from the design, delivery and early operational phases of the project. The energy performance of the case study building is assessed through comparison of designer estimates to detailed sub-meter energy readings obtaining from the building management system.

\subsection{Case Study Building}

The Institute for Manufacturing (IfM) Alan Reece building at the University of Cambridge is a $4380 \mathrm{~m}^{2}$ multipurpose laboratory-office space on the University of Cambridge West Cambridge site. Construction of the facility commenced in February 2008 and the building was officially opened in November 2009. The desire for the building to exhibit sustainable characteristics began early in the concept phase, leading to the implementation of natural ventilation in open plan office spaces and biomass to meet the building's heating requirements [11]. The building is used for both research and teaching purposes, and approximately one third of the total floor space is comprised of mechanically ventilated laboratory workspaces.

In addition to the legislative BRUKL requirements, both BREEAM and Soft Landings principles were applied during the development of the IfM building. Both methods were contractually required as a part of the Cambridge University Estate's internal policy on new building construction. Documentation made available through the Estate was analysed to observe how the implementation of BREEAM and Soft Landings functioned in practice. The documentation included meeting minutes, specification requirements, standards, Estate policies and historical energy performance reports. Further information was gleaned through interviews with the building project management staff from the Estate and building occupants and operators. The building's Energy Performance Certificate was available due to public reporting requirements of the BRUKL.

The BREEAM ambition changed midway through the construction phase from Very Good to Excellent, but the rating was achieved nonetheless; the first building in the University Estate to do so. The Soft Landings Cambridge Work Plan (referred to also as Cambridge Work Plan) implemented during the development of the IfM was customised for the University by concept developer and architect Mark Way in 2006 [12]. The Cambridge Work Plan shares many of the same characteristics as the Soft Landings Framework from the Building Services Research Information Association (BSRIA) and the UK's Government Soft Landings (GSL), the latter of which was developed specifically for application by central government clients $[13,14]$. The use of the Cambridge Work Plan for the case building was neither verified nor certified by external actors.

\subsection{Energy Analysis Approach}

To establish the performance of the case study building, it was necessary to quantify energy efficiency. Meter information from the building's 30 sub-meters was collated from the Building Management System (BMS) in order to establish energy consumption by end-use. Benchmarks for the same end-uses were available using the office Energy Consumption Guide 19 (ECON19) from 2003 [15]. Although the data presented in this guide were collected in the mid 1990s, the comparison is relevant in the context of most end-uses apart from unregulated plug loads, which could be expected to be quite different in the IfM. The aggregate energy consumption (without end-uses) was benchmarked against data from Carbon Buzz, CIBSE TM46 Energy Benchmarks and the Department of Energy and Climate Change (DECC). An overview of these benchmarks is provided in Table 1. 
Table 1. Non-domestic building energy benchmarks for comparison.

\begin{tabular}{ccccc}
\hline & $\begin{array}{c}\text { Energy } \\
\text { Consumption } \\
\text { Guide 19 (ECON19) }\end{array}$ & $\begin{array}{c}\text { TM46 Energy } \\
\text { Benchmarks } \\
\text { (Used in DECs) }\end{array}$ & CarbonBuzz & $\begin{array}{c}\text { Non-Domestic National } \\
\text { Energy Efficiency } \\
\text { Database (ND-NEED) }\end{array}$ \\
\hline Developer & BRECSU & CIBSE & RIBA and CIBSE & $\begin{array}{c}\text { Department of Energy } \\
\text { and Climate Change }\end{array}$ \\
$\begin{array}{c}\text { Established } \\
\text { Building categories }\end{array}$ & 1995 & 2008 & 2008 & 2014 \\
Number of end-uses & 4 & 29 & 35 & 5 \\
Benchmark data & 11 & 2 & 2 & 2 \\
collection period & Mid 1990s & Pre-2007 & $2008-$ present & $2006-2011$ \\
Statistical data & $\mathrm{X}$ & & $\mathrm{X}$ & $\mathrm{X}$ \\
Crowd sourced & & & $\mathrm{X}$ & $\mathrm{X}$ \\
Open access & & CIBSE Guide F, & CIBSE TM46 & \\
Cross-references & & ECON19 & reference & \\
\hline
\end{tabular}

The first of the benchmarks, ECON19, is especially useful due to high resolution of end-uses and data availability for two types of naturally ventilated offices and two types of air-conditioned offices. Because the IfM building uses a mixed-mode system with both ventilation types, a weighted average based on floor area can be used to make a directly comparable metric. Two thirds of the IfM building floor space is naturally ventilated (the remaining third is mechanically ventilated), so a 2:1 weighting of the ECON19 benchmarks "naturally ventilated open plan" and "air-conditioned standard" is used.

The remaining three energy benchmarks are directly comparable to the main metered consumption types of electricity and heating fuels (gas and biomass). Although only two energy end-uses are provided in these benchmarks (considerably fewer than for ECON19), each benchmark is useful for different reasons:

- The ND-NEED benchmark reveals non-domestic building energy use intensity for electricity and gas from a database covering in excess of $20 \%$ of all non-domestic buildings in the UK. The relevant data for this research were collected in 2011, for office buildings between 1000 and $4999 \mathrm{~m}^{2}$ [16].

- CarbonBuzz draws upon open source case study building data contributed by building professionals and represents a dynamic database for university buildings. In this case, the reported actual consumption is used as the benchmark, although prediction data are also available.

- CIBSE TM46 describes the statutory building energy benchmarks to complement the DEC rating procedure, again for university buildings [17].

The Building Logbook, a standard deliverable under British Building Regulations for non-domestic buildings, contained designer estimates for energy consumption. This allowed for comparison of benchmark, design-stage estimates and actual energy consumption that assisted understanding the design expectations and shortcomings. The energy performance information could then be cross-referenced with the findings from the document analysis and interviews in order to begin to assess possible reasons for sub-optimal building operation.

\section{Review of Energy Performance Initiatives Used in Case Study}

\subsection{The Building Regulations UK Part L (BRUKL)}

The Building Regulations UK Part L (BRUKL) on fuel and energy conservation comprises two main methodologies through which a building's energy consumption is estimated and measured. Energy Performance Certificates (EPC) estimate energy consumption based on delivering a pre-defined level of comfort using standardised assumptions on building operation. Display Energy Certificates (DEC) use measured energy consumption from the previous year to rank non-domestic buildings within 29 building typologies (e.g., school, hospital, etc.). Both methodologies use a colour-coded, 
graphical rating scale of energy use ranging from A to G. The BRUKL has implemented both methodologies based upon the requirements of the European Union Energy Performance of Buildings Directive (EPBD) [2].

Energy Performance Certificates use an estimation methodology to calculate the energy that is used by a building in providing its most basic functions of Heating, Ventilation and Air Conditioning (HVAC), lighting and hot water provision. These basic functions are also referred to as regulated loads because they are regulated by the BRUKL. The purpose of the EPC is to allow for a simple, uniform means of comparing the modelled energy efficiency of buildings. Because the production of EPCs is mandatory for all buildings in the UK when built, renovated, sold or leased, there is widespread awareness of relative energy performance amongst the public. The energy consumption estimates used in the creation of an EPC are commonly misinterpreted to represent the entire building's energy use. This can lead to gross underestimation of operational energy use and confusion about the overall impact a building has on the environment [18].

The BRUKL stipulates that a Display Energy Certificate is to be renewed every 12 months and displayed in all public buildings frequently visited by the public and larger than $1000 \mathrm{~m}^{2}$ [19]. This'includes most large governmental and educational buildings. The DEC rating is developed based on the previous year's energy readings, and includes all energy consumed within the building. DECs expire annually due to their dependence on current energy readings.

\subsection{BREEAM New Construction}

On the international stage, the Building Research Establishment Environment Assessment Method (BREEAM), established in the UK, is one of the most commonly used rating schemes in the field of voluntary building environmental assessment methods [20]. Assessment methodologies such as BREEAM and its US equivalent, Leadership in Energy and Environmental Design (LEED), certify buildings based on a point-based rating scheme. Many other green building assessment tools are created using the same principles and are tailored for the requirements of a specific country, such as the Comprehensive Assessment Scheme for Built Environment Efficiency (CASBEE) rating scheme in Japan and Green Star in Australia [21,22].

BREEAM offers points in a diverse range of sustainability categories, of which energy is the largest single category with $19 \%$ of total available points (in 2012) [23]. A high BREEAM rating does not require the achievement of any particular number of energy credits, but rather a minimum number of achieved credits across all categories. Thus the correlation between the BREEAM rating and energy focus is not guaranteed. Further, since BREEAM ratings are granted largely on the basis of design intent and not operational performance, highly rated buildings can perform poorly even in categories that have received many BREEAM credits. For energy consumption, this can be the result of the construction team's poor adherence to building design or inappropriate building user behaviour.

In an analysis of the energy performance "credibility gap", Bordass et al. discuss 22 reasons for the difference between predicted and actual performance [4]. Of these, 13 come at a stage after the building design is complete. A case study in the same paper showed that actual $\mathrm{CO}_{2}$ emissions two years after completion were three times greater than the BREEAM estimates of $\mathrm{CO}_{2}$ emissions.

A study comparing BREEAM buildings with EPCs and DECs in the UK demonstrated a clear disconnect between certification and realised energy savings (taken as being proportionate to DEC rating) [24]. Such studies illustrate the difficulty in translating good design intent into measurable energy savings, and this phenomenon is observed with many voluntary rating schemes, emphasising the need to incorporate use-phase emissions [25].

\subsection{Soft Landings Cambridge Work Plan}

"Soft Landings" was conceptualised by Mark Way when working as a principal architect on the construction of the Centre for Mathematical Sciences at the University of Cambridge in 2002. His intention was to extend the service provided by building designers and contractors such that 
feedback from occupants and managers can become a natural part of the project delivery process [26]. Through this work plan, the project management team and builders were required to participate in regular meetings during a three-year "extended aftercare" period following building handover. This was intended to promptly amend problems that occur during early occupancy and to maintain a regular presence in the building to gather feedback on operation.

A former director of the Cambridge University Estate supported the formalisation of this highly successful approach, enabling a project team to draw together a preliminary guide for Soft Landings in 2004 (referred to hereafter as the Cambridge Work Plan) [26]. The Cambridge Work Plan consists of 17 pages of guidance material, 7 pages of which are checklists of requirements for sign off by the Estate Management and Building Services facilities manager. These occur at the following stages: briefing, pre-handover, post-handover and aftercare for each of the three years following practical completion. The Cambridge Work Plan was utilised in the procurement of the Institute for Manufacturing, as was standard practice for all new buildings in the University Estate at the time of construction.

Since this time, the process has been developed and refined by BSRIA and the Usable Buildings Trust into a series of open access documents, at the core of which is the BSRIA Soft Landings Framework. The Framework, in a similar manner to the Cambridge Work Plan, assesses the different stages of building development from design briefing through to operational feedback [27]. It helps project teams to close the loop between the different phases of building development and to feed back the lessons learnt into the briefing stage of future buildings. Unlike voluntary rating schemes, there are no licensed assessors or means of verification for the Cambridge Work Plan or the Soft Landings Framework. In terms of operational outcomes, the BSRIA Soft Landings Framework includes some more formalised processes for reality checking whereby "designers need to check and refine their energy use targets" [13]. The same guideline suggests that formal reality checking methodologies such as the BSRIA Pitstopping approach could be employed to "ensure that the detailed design and its execution continues to match the client's requirements, the design team's ambitions" [13].

In 2016, the UK Cabinet Office began to mandate the use of Government Soft Landings for central Government building procurement [14]. This initiative is aligned to the BSRIA Soft Landings Framework and its implementation will be parallel to the requirement for Building Information Modelling (BIM) in all Government building projects.

\section{Results}

\subsection{Energy Use Compared to Benchmarks}

Energy benchmarks were used to quantify the relative performance of the case study building. For the case study building four relevant benchmarks were found: ECON19, CIBSE TM46:2008, CarbonBuzz and ND-NEED. The relative merits of each benchmark are summarised in Table 1. The IfM building has a total of 28 electrical meters and sub-meters, one biomass heat meter and two gas meters. Based on the available sub-meter descriptions it was possible to create an "as-performing" energy consumption graph, broken down by end-use. Energy consumption data were available from January 2009 until June 2014. Because of unusual occupancy patterns in the first year of operation (staff occupation of the facility occurred between May and August 2009), only the data from 2010 onwards were used in benchmarking analyses ( 4.5 years in total). The primary electricity meter value was $15 \%$ less than the sum of electrical sub-meter readings during this 4.5 year period meaning that the meters were not accurately measuring the power consumption or were incorrectly installed resulting in double-measurement. This disparity in metered electricity use is taken into account in subsequent figures, by the inclusion of a lower confidence limit where electrical sub-meter energy consumption is multiplied by a factor of 0.85 to bring the total energy use in line with primary meter readings. Raw sub-meter data are additionally included as an upper limit in Figures 1 and 2.

The facility's Building Logbook (a requirement for BRUKL compliance) contains a design stage energy estimate for the IfM. This energy estimate does not precisely detail the end-uses that are 
recorded by the building electrical sub-meters, however it provides a guide to the expected annual energy consumption. The estimate is broken down into three categories:

- electricity for naturally ventilated spaces;

- electricity for mechanically ventilated spaces; and

- natural gas for hot water use.

Users of the Logbook are cautioned about the exclusion of laboratory loads and biomass heating energy consumption from the collective estimate.

\subsubsection{Energy Consumption Guide 19 for Offices (ECON19)}

When compared with metered consumption in Figure 1, laboratory energy use is separated to allow comparison of the office component of energy performance. The results show that the IfM building consumes 10-29\% more energy than a typical office building from 2003 (excluding laboratory loads), and $93-127 \%$ more relative to a good practice building from the same period. The ranges are used to show the lower and upper limits based on uncertainty in electricity meter readings.

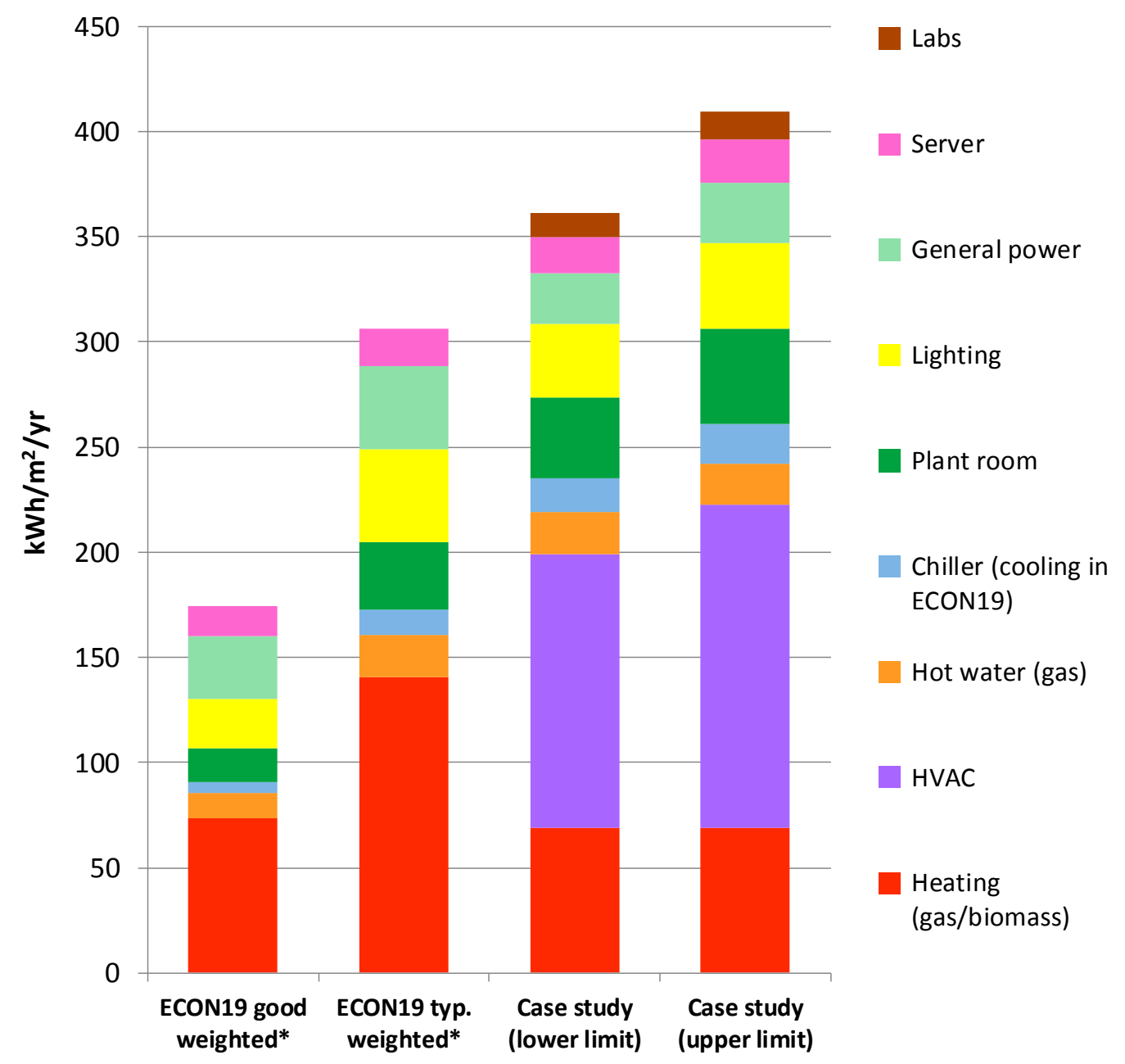

Figure 1. Case study building end-use energy consumption with floor-area weighted ECON19 "Good Practice" and "Typical" benchmarks for offices. Upper limit represents raw sub-meter data whilst lower limit electrical end uses are adjusted (factor: 0.85 ) to account for $15 \%$ disparity between sub-meters and main meter. ${ }^{*}$ Weighting: $2 / 3$ naturally ventilated open plan and $1 / 3$ air-conditioned standard in line with floor space allocated to each ventilation strategy in the case study building. 


\subsubsection{Low End-Use Resolution Benchmarks}

The three energy remaining energy benchmarks are plotted together with IfM energy performance in Figure 2 below. This illustrates that the IfM building performs worse than the non-domestic building stock average, despite receiving a high BREEAM rating. Total metered consumption is $49-69 \%$ higher than both the ND-NEED statistics for offices and the CarbonBuzz metric for university buildings, and 9-24\% greater than the benchmark from CIBSE TM46 (excluding laboratories). The biomass heating energy consumed at the IfM is less than the heating category in the benchmarks, meaning that the high total energy consumption is largely due to much higher electricity consumption relative to benchmarks and the Logbook estimate.

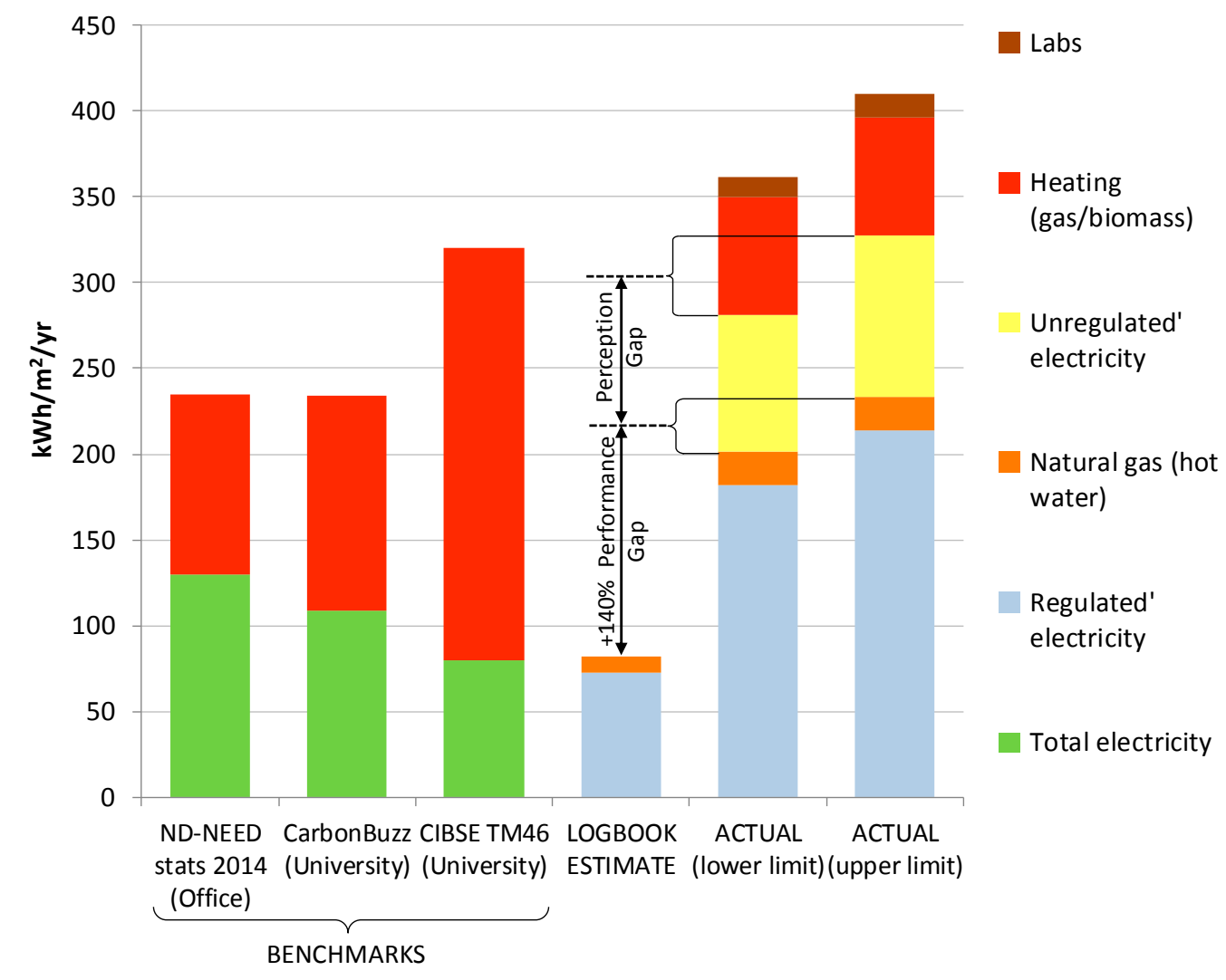

Figure 2. Energy Consumption of the IfM building and comparative energy benchmarks/logbook estimate. Perception gap is used to refer to the unregulated loads that are not included within the scope of the logbook estimate.

It is assumed that the estimated electricity consumption from the Building Logbook is inclusive only of "regulated" loads given that the Logbook is a statutory requirement of the BRUKL. In order to quantify the performance gap, the unregulated loads (which are not reported upon in the Building Logbook) must therefore be excluded. Since the unregulated loads are not included within minimum standards from BRUKL, their contribution to the energy performance gap is a matter of scope definition rather than issues with building performance. The authors have thus adopted the Green Construction Board's terminology "perception gap" to refer to the unregulated or "process" loads (those that are not within the scope of the BRUKL). It is helpful to consider the difference between estimated and actual energy consumption in this manner such that the issue of scope (the perception gap) is separated from issues related to actual building performance [28]. The regulated electricity loads were taken to be the chiller, HVAC and lighting loads from Figure 1. Plant room loads were excluded due to the operation of machinery here for the laboratories. The result is an energy performance gap of $140 \%$, as seen in Figure 2. 


\subsubsection{Designer Energy Estimates Prior and during Early Operation}

The energy performance gap quantified above relies upon a Building Logbook estimate provided by the designers of the IfM building. Subsequently, the University Estate created an energy-use Key Performance Indicator (KPI) report for the IfM [29]. These KPI reports are commonly produced for new buildings in the University as a form of reporting and feedback with the building designers in the three-year post-completion period governed by the Cambridge Work Plan [30]. The report suggests that, between 2010 and 2011, a 9\% decrease in total energy consumption occurred after which point energy use steadied [29]. This may have been the result of fine-tuning during 2010, potentially due to aftercare and commissioning processes. However, BMS data reveal that after a steadying in energy consumption in 2011, the energy consumption increases again in every year after 2012.

During the first full year of operation (2010), the KPI report held by University Estate shows a large energy performance gap against the Building Logbook estimate (from March 2009). The designers were asked on at least two subsequent occasions to revise their estimates based on findings from the report (actual consumption is indexed and reported each year), as illustrated in Figure 3.

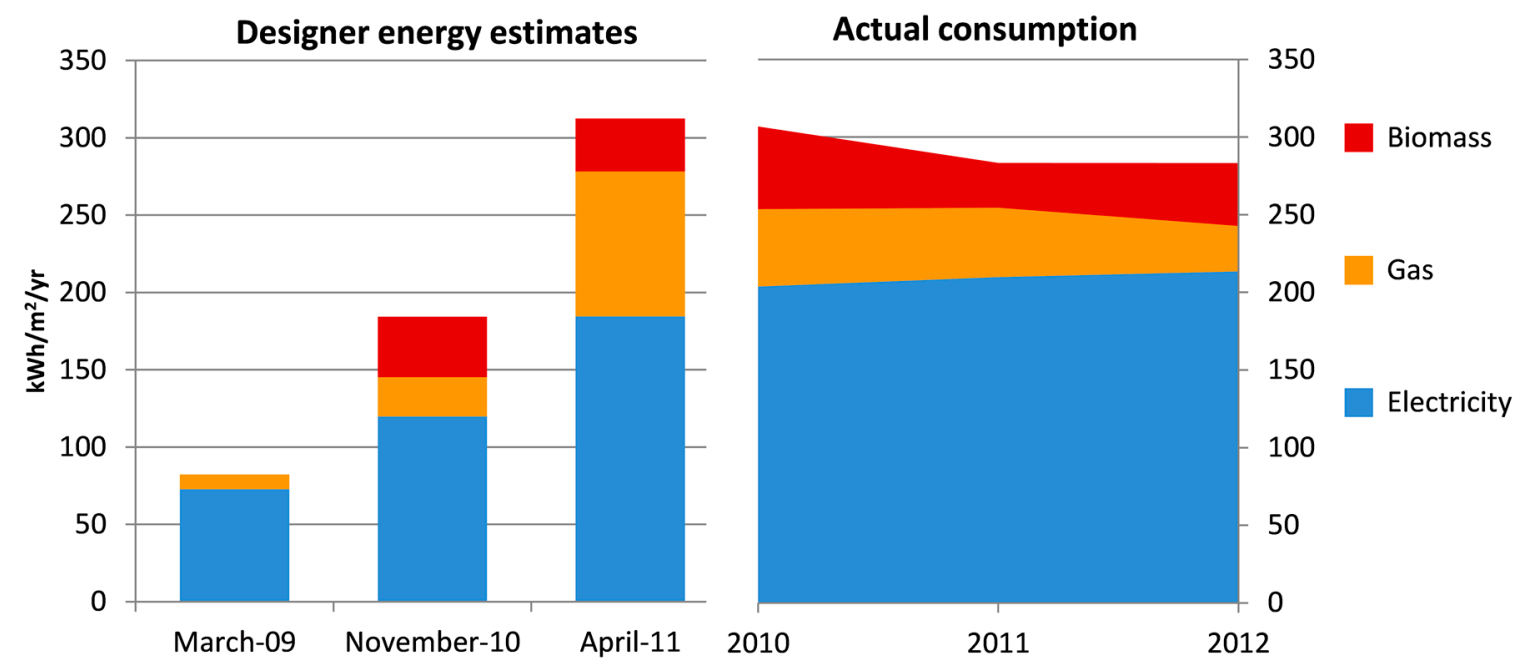

Figure 3. Designer energy estimates compared to primary metered consumption. Data obtained from internal report [29].

The University Estate sought for the design team, still contractually bound to the Soft Landings conditions of the Cambridge Work Plan, to produce new estimates that would reflect the real performance of the building (or to suggest building adjustments to otherwise narrow the gap between energy estimate and consumption). It is apparent in Figure 3 that the estimates for energy consumption are incrementally adjusted upwards towards the actual value over the course of two subsequent revisions. This is despite the availability of actual energy consumption data from 2009 and 2010 prior to the second energy estimate in November 2010. This shortcoming in the revised (second) estimate to actual consumption suggests that the design team continued to underestimate energy consumption due to building specific conditions (operational hours, user behaviour, etc.) or maintained overly optimistic expectations about a reduction in actual consumption (from building commissioning, facilities management changes, fine-tuning or similar). The mismatch was rectified in a new revision produced in April 2011, nearly two years after the first building occupants moved in.

The contract conditions of the design team and the requests for revision to designer estimates were not available, however it is apparent that there is little consequence to the designer when making an inaccurate energy estimate. This could be the result of a heavy focus in the early building procurement phases on design-based rating schemes such as BREEAM, which do not test the operational accuracy of energy estimates. This allows for many overly optimistic assumptions to be made repeatedly 
concerning occupant behaviour and building operation as energy performance data are rarely fed back to the design team. The IfM case study is somewhat unusual in the building industry given the contractual involvement of the designers post-handover-through the extended aftercare process set out by the Estate's Cambridge Work Plan. The requests for revised estimates from the Estate allowed the designers to look closely at the energy performance gap for their own building. This could improve designers' understanding of operational building conditions and inform future energy estimates on new builds or refurbishments through a cyclical learning process.

\subsection{Review of Soft Landings Cambridge Work Plan}

Soft Landings has been a requirement since the University commissioned the Soft Landings Cambridge Work Plan in 2006 [12]. This approach was a contractual requirement for the procurement of the IfM building, and the first 12 months of meeting minutes concerning Soft Landings were critically evaluated against the Cambridge Work Plan requirements. Other documentation including reports for BREEAM certification, practical completion and Post-Occupancy Evaluation (POE) are cross-referenced in order to verify compliance with the Cambridge Work Plan.

At the briefing stage, the Work Plan makes a number of suggestions of relevance for the realisation of energy efficient building operation. One of these concerns the setting of environmental performance targets that "must satisfy the test of being (i) unambiguous, (ii) measurable and (iii) of some value". Energy targets must consider the effective use of a BMS, a realistic setting of expectations and a design solution that takes into account the need for users to have some control. Given that sub-metered data were not adequately utilised in the review of energy targets (Figure 3), and that the scope of the target in the initial and subsequent target reviews was not clear (leading to a tripling of the expected energy consumption), it could be seen that these criteria are not well met. Simultaneously, building management staff have a large influence over a building's operational performance, and it could be that a significant percentage of the difference in initial and final estimates from designers is due to poor management practices.

A summary of key requirements and evidence from meeting minutes is presented in Table 2. Although not all of the key deliverables have direct energy outcomes, they have been included to provide a more complete picture concerning the implementation process for the Cambridge Work Plan at the University Estate. The comparison reveals a poor match between the intentions and executed actions. The highly variable attendance at the monthly or bimonthly meetings suggests that the Cambridge Work Plan was not treated as a priority among the designers and contractors (or potentially client) at the IfM. The Post-Occupancy Evaluation (POE) was completed in October 2011 by the internal project management team from the University Estate. This was not an explicit recommendation in the Cambridge Work Plan, but is in line with the general philosophy of extended aftercare. Bordass et al. [31] recommend that POE should be independently performed using formal guidelines from the Usable Buildings Trust or other sources. Internal evaluation reduces the effectiveness of such a document due to a potential conflict of interest (dependent on the review process). The POE document shares many similarities with the Practical Completion Report and has no critical comments concerning the energy performance of the building. Additionally a Building User Survey was not referred to, despite this being an explicit requirement in the first year of aftercare in the Cambridge Work Plan: "an independent Occupant Survey is included as part of the Post Handover Aftercare stage" [12]. 
Table 2. Comparison of Soft Landings Cambridge Work Plan requirements and meeting minutes in the first year following practical completion.

\begin{tabular}{|c|c|c|c|}
\hline Key Deliverables & Requirements (Design Intent) & Observations from Minutes & Evidence \\
\hline Pre-Handover Stage & \multicolumn{3}{|c|}{ Before User Occupancy } \\
\hline Commissioning time & $\begin{array}{l}\text { Allocated time between build completion and } \\
\text { occupation to allow for fine-tuning of building } \\
\text { equipment and components. }\end{array}$ & $\begin{array}{l}\text { The commissioning report was an item on every } \\
\text { meeting agenda. Commissioning appeared to be well } \\
\text { executed with sufficient time allocated. }\end{array}$ & Good \\
\hline Training programme for FM staff & $\begin{array}{l}\text { To ensure that FM staff are adequately prepared for } \\
\text { post-handover. }\end{array}$ & $\begin{array}{l}\text { Training was arranged from specialist installers such as } \\
\text { security systems and clean room laboratories. }\end{array}$ & Good \\
\hline $\begin{array}{l}\text { Building Management System (BMS) } \\
\text { demonstration for FM staff }\end{array}$ & $\begin{array}{l}\text { Demonstrate key facilities and trend logging to allow } \\
\text { for future reviews of the actual performance and } \\
\text { fine-tuning of systems. }\end{array}$ & $\begin{array}{l}\text { BMS training was discussed and scheduled over several } \\
\text { meetings. Minutes after scheduled time state that BMS } \\
\text { training is outstanding. }\end{array}$ & Poor \\
\hline User migration planning & $\begin{array}{l}\text { Design team to assist mitigate the impact of any } \\
\text { on-going site activities with incoming user } \\
\text { requirements. }\end{array}$ & No evidence. & $\mathrm{N} / \mathrm{A}$ \\
\hline Arrange aftercare team "home" & $\begin{array}{l}\text { Aftercare team required to assist with issues in the first } \\
\text { weeks of occupation, and should be based in an } \\
\text { accessible "home" where occupants can seek assistance. }\end{array}$ & $\begin{array}{l}\text { A semi-permanent aftercare team home is not } \\
\text { discussed, and meetings are held on an infrequent and } \\
\text { irregular basis in different rooms. }\end{array}$ & Poor \\
\hline Compile Building User Guide & $\begin{array}{l}\text { To help building users to better understand and operate } \\
\text { the building efficiently as envisaged by the design team. }\end{array}$ & $\begin{array}{l}\text { Draft version of the Building User Guide is circulated } \\
\text { and updated after feedback; however this item remains } \\
\text { outstanding at every subsequent meeting. }\end{array}$ & Poor \\
\hline Operations and Maintenance (O\&M) & $\begin{array}{l}\text { Verify content of O\&M guidance to ensure } \\
\text { completeness. }\end{array}$ & $\begin{array}{l}\text { Discussed at length, and scope expanded to include the } \\
\text { work of sub-contractors. }\end{array}$ & Good \\
\hline Early Aftercare Stage & \multicolumn{3}{|c|}{ Immediately Post-Occupancy for 4-8 Weeks } \\
\hline Provide resident on-site attendance. & $\begin{array}{l}\text { To respond to emerging issues. Expectation to be in } \\
\text { attendance 1-2 days per week. }\end{array}$ & $\begin{array}{l}\text { No mention was made of regular attendance during the } \\
\text { occupancy phase-in. Additional meetings were } \\
\text { scheduled in response to particular issues that required } \\
\text { quick resolution. }\end{array}$ & Poor \\
\hline Building user guidance & $\begin{array}{l}\text { Provide focus group meetings with new users to } \\
\text { disseminate building operation information. }\end{array}$ & No evidence. & Poor \\
\hline Technical guidance & $\begin{array}{l}\text { To allow for smooth transition to operation by client's } \\
\text { FM team. }\end{array}$ & $\begin{array}{l}\text { Training from pre-occupancy phase appears to cover } \\
\text { the specialised technical information handover. }\end{array}$ & Good \\
\hline Communications and walkabouts. & To encourage feedback and observe occupation usage. & No evidence. & N/A \\
\hline
\end{tabular}


Table 2. Cont

\begin{tabular}{|c|c|c|c|}
\hline Key Deliverables & Requirements (Design Intent) & Observations from Minutes & Evidence \\
\hline Aftercare Remainder Year 1 & \multicolumn{3}{|c|}{ After the "Early Aftercare Stage" Until 1 Year Post-Completion } \\
\hline Aftercare review meetings & $\begin{array}{l}\text { Continue to have designer and constructor presence in } \\
\text { monthly Cambridge Work Plan Meetings. }\end{array}$ & $\begin{array}{l}\text { Meetings continue to be held on site after occupancy } \\
\text { commences and official opening occurs. }\end{array}$ & Good \\
\hline Log and review energy usage & $\begin{array}{l}\text { Provide comparison against energy targets and assist } \\
\text { fine tuning. }\end{array}$ & $\begin{array}{l}\text { BMS data manually read prior to data connection to } \\
\text { central Estate. Energy targets are not mentioned. }\end{array}$ & Poor \\
\hline $\begin{array}{l}\text { Fine tune systems and record changes in } \\
\text { usage }\end{array}$ & $\begin{array}{l}\text { To adjust for seasonal change as necessary, and make } \\
\text { notes of any changes to system operation in the } \\
\text { building logbook. }\end{array}$ & $\begin{array}{l}\text { Seasonal commissioning scheduled as a part of } \\
\text { preventative maintenance. Records from this are not } \\
\text { kept in the logbook or mentioned in later minutes. }\end{array}$ & Poor \\
\hline Commission occupant survey & Independent survey of occupant overall satisfaction. & $\begin{array}{l}\text { No mention of formal survey. Instead general opinions } \\
\text { of some user representatives are used (not } \\
\text { independent). }\end{array}$ & Poor \\
\hline Year 1 review & $\begin{array}{l}\text { To review overall building performance and } \\
\text { information from first year of Cambridge Work Plan. }\end{array}$ & $\begin{array}{l}\text { No evidence, however the meeting records cease in } \\
\text { January, } 10 \text { months after practical completion. }\end{array}$ & $\mathrm{N} / \mathrm{A}$ \\
\hline
\end{tabular}




\subsection{Review of BREEAM}

The University Estate has, since 2008, maintained a policy where all new buildings are required to target a BREEAM "Excellent" rating and to achieve a minimum rating of "Very Good" "in cases where there are good and explicit reasons why an Excellent rating could not be achieved" [32]. The certification document for the BREEAM Excellent rating was analysed to consider the potential impact of the BREEAM certification on energy performance of the IfM. The document provides evidence for all credits that the building is eligible for using the Bespoke BREEAM 2006 rating scheme.

The "Final Certification Report Issue to BRE" for the building was created in February 2009, well before the first occupants moved into the facility in May of the same year. One of the awarded points under the category management was the development of a Building User Guide (BUG) for use by building occupants/tenants and non-technical building manager. It was an awarded credit point in the BREEAM certification report based upon a file note where the creation of this document was promised, however none of the 13 surveyed building occupants were aware of the document. As the name suggests, this document is tailored to meet the needs of users, providing guidance on building operation to ensure thermal comfort and efficient use. The IfM Practical Completion Report indicated that training sessions on the building's systems were run with users and maintenance teams prior to handover, but the information was not made available in the form of a BUG. Given the high turnover of building occupants, this may lead to a poor user understanding of the operation of the mixed ventilation and thermal comfort systems in the IfM building.

Under the category of energy, a total of 19 credit points are available, the largest single category in the Bespoke BREEAM 2006 rating scheme (from a total of 119). Twelve points were achieved, equivalent to $63 \%$ of the total available in this category. The total percentage of achieved BREEAM credit points in the IfM was $68 \%$ (81 points). The largest source of points was the subcategory "reduction of $\mathrm{CO}_{2}$ emissions"- for which 15 points were available. A dynamic simulation model produced by the building designers showed that the IfM facility's building emission rate of $21 \mathrm{~kg} \mathrm{CO}_{2} / \mathrm{m}^{2}$ per annum should represent an 18.4\% improvement over the BRUKL Target Emission Rate (TER) requirement for non-residential new buildings in 2006. Using BREEAM's conversion table, this improvement was awarded nine points. Single points were awarded in the following subcategories: external lighting, sub-metering of areas/tenancy and sub-metering of substantial energy uses, whilst one point concerning fume cupboards was not sought.

The energy credits awarded by BREEAM to the IfM suggest that the building is, at the design stage, better than the BRUKL TER requirement that applied to it. This is logical given the function of building regulations as a minimum standard (a means through which all buildings seeking BREEAM certification in 2006 could receive points provided the expected energy consumption was more than $1 \%$ over the BRUKL threshold). However, energy performance results from Section 4.1 of this paper show that the building performs considerably worse than all four benchmarks that cover similar building categories to the IfM. The fact that the certification report was finalised three months prior to occupancy commenced and nine months prior to official opening demonstrates that the BREEAM certification is fully reliant on design ambitions. No follow-up occurred post-occupancy to check any of the credit points awarded, most importantly concerning the energy performance of the building-which would presumably be considerably worse than the simulated $21 \mathrm{~kg} \mathrm{CO}_{2} / \mathrm{m}^{2}$ per annum for which nine points were awarded. Without these nine points, the building would not have received a BREEAM Excellent rating. After weighting, the nine points are worth $6 \%$ of the total available points.

\subsection{Review of the UK Building Regulations Part L (BRUKL) Implementation of the EU Energy Performance of Buildings Directive (EPBD)}

For the IfM building, the BRUKL stipulates that both an Energy Performance Certificate (EPC) and a Display Energy Certificate (DEC) should be created. Both certificates should be prominently displayed (usually in a building lobby) so that building users can see them. An EPC was available for the facility, which was submitted to the publically available Non-Domestic Energy Performance 
Certificate Register (NDEPC Register) in March 2009 [33]. The EPC showed an energy performance asset rating of 36 (or a rating of $B$ on a scale from A to G). The certificate additionally states that a new building similar to the IfM facility could have a rating of 49 (also a B-rating) or 95 (D) if typical of the existing building stock. The creation of the EPC, similar to the BREEAM certification report, was produced prior to building occupancy, and well in advance to final building commissioning. The results are purely dependent on dynamic simulation models and which are considered valid for a 10-year period after creation.

The prominent display of a verified DEC (updated annually) is a legislated requirement for public buildings larger than $500 \mathrm{~m}^{2}$, and is a verifiable and familiar form of building energy benchmarking. When implemented and updated each year, a DEC can reveal the trends in energy consumption over time and provide building occupants with information on their facility's energy performance. This would also form a verifiable means through which performance-based certification and building design can occur. The IfM's lack of DEC was confirmed through searches of the public NDEPC Register and in conversations with EMBS staff and building occupants. This could be the result of an imprecise definition of the facility that results in its exclusion from the category of public buildings (although it is a public university building, it is not fully open to the general public). It is however not unlikely that the document was created but never formally approved or uploaded to the registry of DECs. Given the fact that many other University Estate buildings are listed in the NDEPC Register, this would suggest that the latter case is more probable, which raises concerns about the follow-up of legal requirements from the BRUKL.

\section{Discussion}

This paper reviews the energy performance impact of three processes that were implemented during the development of the IfM building in Cambridge: BREEAM, the Cambridge Work Plan and Part L of the UK Building Regulations (BRUKL). The results of the analyses show that expectations concerning energy consumption from all three processes are not entirely met in the case study building. The IfM building has however only implemented two voluntary methods beyond the requirements of the BRUKL. To consider some other industry guidelines, Section 5.1 presents four alternative methods currently available for application to the non-domestic building sector in the UK. These are methods are subsequently discussed in light of their potential contribution given the issues raised in the case study in Section 5.2.

Although the methods chosen do not focus solely on energy performance, this article's focus made this a primary criterion for selection. The additional methodologies should also provide a unique perspective, thus limiting the selection of similar building environmental assessment methodologies to BREEAM for example. Amongst the available voluntary rating schemes, Passivhaus and the Living Building Challenge (LBC) were selected for their unique approaches with rigorous building envelope criteria and performance-in-operation focus respectively, despite their limited implementation in the non-domestic building sector.

Voluntary guidance documents that do not provide certification were also considered. In the UK, there are a number of commercial entities that provide voluntary guidance documents, two of which were considered to be of relevance for this paper: BSRIA and CIBSE. BSRIA (together with the Usable Buildings Trust) now maintains documentation for the Soft Landings concept. CIBSE meanwhile has created two technical memoranda of relevance in addition to the benchmarking documents in Table 1: TM54 and TM22 for operational energy performance estimation and energy assessment respectively. Other documents such as the Royal Institute of British Architects (RIBA) Plan of Work were not considered in this paper, primarily as they are not as focussed upon the energy performance of buildings. 


\subsection{Alternative Initiatives to Address Building Energy Efficiency in Operation}

\subsubsection{Passivhaus Voluntary Building Rating Scheme}

The Passivhaus concept originated in Germany for residential housing in 1996, where it has mainly been applied in the high-end domestic building market [34]. Although the Passivhaus Institut (sic) provides certification, the definition of a Passivhaus relies more upon a set of fundamental principles. Arguably the most critical of these is a so-called fabric first approach using a high standard of thermal insulation and air tightness to minimise heat losses [35]. Rather than prescribing a minimum standard of insulation, the Passivhaus Institut requires that new buildings can provide a comfortable indoor climate without exceeding $15 \mathrm{kWh} / \mathrm{m}^{2}$ per annum for space heating or cooling. Total primary energy use must also be under $120 \mathrm{kWh} / \mathrm{m}^{2}$ per annum, inclusive of all energy end uses within the building. No studies have been located during this research which test non-domestic Passivhaus projects for operational compliance with these two minimum requirements.

For the purpose of certification, Passivhaus buildings do not need to provide actual energy consumption data. Instead, the heating and cooling demand is verified by an accredited building certifier. The process is however much more elaborate than that used in BREEAM, due to the rigid targets and possibility of receiving certification in many different types of climate and building occupancy environments. Thus many of the input characteristics in determining energy demand must be calculated specifically for the individual project. Other characteristics that directly impact energy use are verified through physical tests, such as air tightness.

\subsubsection{Living Building Challenge Voluntary Building Rating System}

Established in 2006, the Living Building Challenge (LBC) is emerging as one of the most stringent voluntary commercial rating schemes for energy efficient buildings [36]. Unlike the two aforementioned rating schemes, a LBC certificate cannot be achieved until 12 months of operation has been completed and verified. The third generation of the LBC, administered by the International Living Future Institute pushes the boundaries of building certification into the realm of regenerative design: moving beyond doing less bad to "doing good". In the context of energy, LBC's hallmark "Living Building Certification" requires making a net positive contribution to energy availability through renewable sources. A total of $105 \%$ of a project's annual energy requirements must be provided through on-site renewable energy [37].

However, the Living Building Certification includes a total of 20 imperatives under seven performance areas or "petals", of which energy is only one. Thus, for buildings focusing on energy performance a separate Net Zero Energy Building Certification was created with only four imperatives [38]. At the time of writing, a total of 45 buildings have achieved certification in either of these two categories, with many more in the process of certification. On the basis of certification not being awarded prior to 12 months of operation, it can be understood that all certified buildings have met the design requirements of net zero energy. Whilst the requirement to produce energy sufficient to cover demand may naturally lead to a reduction in designed energy demand, there are no specific requirements for energy consumption. Thus a property could consume relatively large amounts of energy so long as it is offset by equivalent (or higher) production. At this stage, no academic articles have been observed investigating LBC rated buildings for energy performance.

\subsubsection{CIBSE TM54: Evaluating Operational Energy Performance at the Design Stage}

CIBSE collated much of the existing knowledge on the performance gap problem in order to release Technical Memorandum 54 "Evaluating Operational Energy Performance of Buildings at the Design Stage" in late 2013. The memorandum guides building designers on how to "turn low energy designs into low energy buildings that achieve the design energy targets" by providing "clear guidance on how to evaluate operational energy use more fully, and accurately, at the design stage" [39]. Utilising TM54 requires detailed building information that can be input into a Dynamic Simulation Model (DSM) 
for the running of high and low-end scenarios. This software is often used in energy simulations of buildings, and is frequently required in building rating schemes including BREEAM and in the creation of EPCs. Through close collaboration and discussion with the building end-users and management team, other building-specific factors can be determined. This eliminates many of the issues associated with the BRUKL standardised assumptions on building utilisation and operational characteristics.

CIBSE TM54 is a technical guidance document (memorandum) that acts as a guide for building professionals. No certification is provided from analysis, however some private sector practitioners are beginning to offer TM54 validation. The results can be used to inform clients about realistic energy consumption guidelines, helping them to plan for running costs once their project is in operation. It is also one of the few guidelines that attempts to model actual energy consumption based on user input, rather than standardised values from BRUKL.

\subsubsection{CIBSE TM22 Energy Assessment and Reporting Methodology}

CIBSE's main other contribution in terms of energy performance of buildings is TM22, a spreadsheet tool for energy analysis of buildings at either the design or operational phase. This tool embeds various building energy benchmarks from TM46, a technical memorandum from the same institution, in order to provide a comparison at the reporting stage. A third revision of the original document from 1999 was not publically released, but was piloted for use in Innovate UK's Building Performance and Evaluation project which ran from 2011 to 2015 [6]. The revised tool allows for the categorisation of electricity consumption into 20 end-uses, together with matching the 29 building typologies available in CIBSE TM46 on Energy Benchmarking [40]. This is especially useful because it is these same typologies that are used in the creation of DECs.

Similarly to CIBSE TM54, TM22 does not provide certification, acting only to inform building professionals conducting an energy performance assessment. Sub-meter data can be manually imported into the spreadsheet from the Building Management System to create a detailed analysis that splits energy consumption by end use. This requires parity of main meter and sub-meter readings and sub-meter descriptions for this to be of value.

\subsection{Lessons Learnt from Case Study Building and Potential of Alternative Energy Performance Initiatives}

\subsubsection{Implementation and Revision of Client Building Policy}

The Cambridge Work Plan policy used by the University dates from 2006 and since this time, BSRIA has significantly advanced the available guidance on Soft Landings [27]. It is important not only that policy is up-to-date, but that it is well implemented. The findings from the implementation of the Cambridge Work Plan on the case study building (Table 2) show that little of the design intentions are well executed in reality. This is particularly the case for the internal Post-Occupancy Evaluation (POE), which Bordass et al. suggest should always be independently performed using formal guidelines from the such sources as the Usable Buildings Trust [31].

The contractual agreements used by the Cambridge University Estate do not appear to have been sufficient to ensure appropriate implementation of the Cambridge Work Plan for the case study building. A revision of these contractual obligations and development of contingency plans (especially concerning liability) in the event of a breach in expectations would assist in the smooth resolution of post-occupancy issues. An alternative approach could be to incorporate Soft Landings concepts into a licensed post-occupancy review approach with a rating and verification process together with marketable certificate, in a similar manner to the Living Building Challenge and other rating schemes [37]. Although the Cambridge Work Plan makes many of the expectations very clear, breaches are repeatedly observed in the case study. Without some form of improved project management, follow-up, contractual obligation or verification, changes in the implementation of Soft Landings concepts are unlikely to occur. 
The University Estate's desire regarding all their new buildings is for the delivery of exemplary sustainable buildings to manageable timescales and budgets [32]. BREEAM, together with the Cambridge Work Plan, were the preferred mechanisms for achieving this in the case of the IfM building. However it is revealed in this paper that the BREEAM rating received by the case study building is not correlated with improved energy performance, in line with much of the literature on BREEAM and energy use. Indeed the Excellent rating is in part a result of a design-stage simulation model that suggested the IfM building would consume 18\% less energy than the Target Emission Rate requirement from BRUKL in 2006. The benchmarking performed in this paper shows that the facility exceeds average energy consumption for four separate benchmarks (some of which are representative of the entire office building stock). This suggests that many of the nine BREEAM credit points received for the facility would be lost if operational energy performance was taken into consideration-putting the BREEAM "Excellent" rating at risk. Thus, a rewording of the sustainability aspirations to include verified energy efficiency in operation could be a powerful clause in building contracts to ensure that both designer and client expectations are met. This can also be achieved through specification of voluntary standards such as the Living Building Challenge for very high performing buildings and through use of DEC grading for other buildings (for example the delivery of a minimum B standard DEC within a specific building typology). Although the BRUKL enforces the EU Energy Performance of Buildings Directive, a Display Energy Certificate was not available for the IfM, which potentially raises concerns about the follow-up of legal requirements from the BRUKL.

It is important to note that the contractual arrangement concerning the Cambridge Work Plan between the designers and the University Estate was not available, and firm conclusions are difficult to make without knowing the conditions by which the relevant parties were working together. The fact that the procedure was not verified or certified could have been a significant factor contributing towards the poor compliance between Cambridge Work Plan requirements and outcomes extracted from the meeting minutes. Alternatively, the contractual arrangement may not have allowed for the extra hours needs to resolve issues or the University Estate may have opted to disregard the shortcomings discovered.

\subsubsection{Capitalising upon Energy Data in Practice}

One of the principal findings from research into the case study building has been that the management team does not capitalise fully upon the presently available energy data to assess building energy performance. Regular detailed reporting on energy data would have quickly uncovered the errors in the BMS sub-meter reporting and allow for resolution of this issue early. Reliable sub-meter data can then be used by building designers as a part of an extended aftercare program (as recommended in Soft Landings) to pinpoint energy saving opportunities. Whilst Key Performance Indicator reports are created to compare estimated and actual consumption during the three-year post-completion period, there is no reporting at the sub-meter level or temporal data analysis of main energy meters. Such an analysis would have very quickly uncovered the disparity in electrical meter readings at the IfM.

The energy estimates were adjusted incrementally upwards on two occasions many months after building handover, suggesting designers were not well prepared to make predictions reflective of operational performance, despite the adoption of the Cambridge Work Plan process. A slow learning rate in light of building performance evidence indicates the need for improvements in the POE review process and better cooperation between designers and operators of buildings. That information is in some cases being fed back from operation to design and only partially acknowledged illustrates that performance based verification needs to be tied into the building contracts.

Real time reporting of energy consumption trends and detailed reporting against University-specific benchmarks and targets is arguably one of the principal benefits of running BMS systems. However this data is presently a mostly untouched gold mine of data for identifying areas for energy optimisation. A peak to baseload energy consumption ratio could be used as a starting 
point for poor building energy performance (where high values indicate abnormal out-of-hours energy use). The Passivhaus certification has rigid guidelines concerning acceptable energy consumption for space heating and cooling of $15 \mathrm{kWh} / \mathrm{m}^{2}$ per annum. Whilst the case study building does not meet this requirement, the comparison of a rigid guideline with real time consumption information could form a basic indicator. With improvements in sub-metering resolution, the energy analysis potential can extend to cover the approaches outlined by TM22:2012 and TM54 amongst many others.

To expect any change in the data management practices with respect to non-domestic building energy efficiency, the task should usually become a tangible responsibility for one or more employees. To avoid tasking time-poor facilities staff with additional remits, it is proposed that dedicated personnel are given the principal task of overseeing energy in the building portfolio (assuming the portfolio is sufficiently large). Ideally they would be placed within the existing teams which oversee the BMS maintenance and would be thus well-placed to observe and react to sub-optimal building energy performance. In the case of commercial buildings, this service could be provided by real estate management companies, depending on the nature of existing agreements for maintenance and management. The specialised knowledge of such staff would allow quick identification of unusual energy trends and resolution through a centralised maintenance team.

\subsection{Building Portfolio Management}

Although not used in this case study, the University Estate has applied a number of other initiatives to reduce energy consumption in its operational buildings. These are motivated in large part by the 2010 release of the Higher Education Funding Council for England (HEFCE) report titled "Carbon Reduction Target and Strategy for Higher Education in England" [41]. The HEFCE report sets emission reduction targets of $34 \%$ by 2020 for emissions that are associated with electricity consumption or that otherwise arise directly from sources that are owned or controlled by universities (including all forms of building energy consumption, but also vehicle fleet operation).

Existing literature points to three main initiatives the University Estate has taken in response to the report: the Energy and Carbon Reduction Project (ECRP), the Electricity Incentivisation Scheme (EIS) and the establishment of the Energy and Environment Coordinators Network (EECN) [8]. The ECRP is a technological initiative to fund the implementation of innovative strategies for energy reduction on the five largest energy-intensive departments in the Estate. The Gurdon Institute, focused on developmental and cancer biology, was one of the five selected departments in the ECRP project and cut its monthly electricity use by 35\% between December 2010 and December 2015 [42]. This was enough to meet the HEFCE requirements, but involved the use of considerable extra funds that are not normally accessible to most building portfolio managers. The EIS incentivises the meeting of departmental electricity consumption targets with financial reward or penalty, whilst the EECN was established to assign responsibility to one individual in every department who is tasked with promoting departmental level behavioural change related to energy and environmental actions. Despite being implemented in 2008, the EIS was not discussed in documentation relating to the IfM, but its effectiveness for a selection of other Estate buildings is discussed elsewhere [8]. The effect of the behavioural change initiatives promoted by the EECN has not yet been evaluated.

These examples from the Estate building portfolio managers demonstrate the potential good management has for reducing energy consumption and meeting emission reduction targets. The EIS has particular promise for other building portfolios, whether private or public-due to the financial enticement for tenants or occupants to actively seek energy saving opportunities. Subsidies similar to the ECRP are more difficult to justify at a building portfolio level due to the need for significant funding.

\section{Conclusions}

The case study IfM facility is a well-functioning building in many respects. BREEAM, Soft Landings Cambridge Work Plan and BRUKL were all employed in early phases of building development, in part to ensure a high standard of energy performance. However, none of these 
were able to deliver operational energy savings compared to industry benchmarks, despite the creation of ambitious energy targets at the design stage. The creation of a Display Energy Certificate (DEC) is the only legislative requirement (under BRUKL) concerning performance verification in the UK (as they are in most EU countries), whilst the voluntary rating schemes Living Building Challenge and Passivhaus also have strong written clauses concerning the follow-up of operational energy performance. However, since building performance verification is, by its very nature, connected to the follow up of buildings post-handover, it is likely going to be a core element for future progress with building energy efficiency. Without performance verification or alternative measures with an economic impact, there remains little incentive to alleviate the energy performance gap, as was observed in this case study's use of the Soft Landings Cambridge Work Plan. The three voluntary guidance documents reviewed additionally have a market penetration problem to resolve when considering the broadening suite of tools disposable to building designers and clients.

The voluntary and partially-enforced schemes introduced in the case study building lacked strict follow-up or post-handover consequences for the design team. This applies to both BREEAM and the bespoke Soft Landings policy used by the Cambridge University Estate. This sheds light on the need for more detailed or binding contracts used in building procurement to cover at least the common problems that appear after building handover. It is necessary also to bring designer expectations and operational energy performance in line with each other, through a focus on delivering buildings as designed. This requires more focus (and thus share of budget) upon the delivery of realistic design stage estimates and a rigorous commissioning/aftercare process. To meet the binding energy and climate targets in the UK the non-domestic building sector must reduce its energy consumption. Whilst much progress has been made, there remains low-hanging fruit in the form of performance verification. If effectively integrated into existing building environment assessment methods and guidance documents, this represents a big step towards achieving a more energy-efficient building sector.

Author Contributions: Ray Pritchard and Scott Kelly conceived and designed the study; Ray Pritchard performed the data collection, analysis and write-up; and Scott Kelly contributed to the analysis and discussion.

Conflicts of Interest: The authors declare no conflict of interest.

\section{References}

1. Department of Energy and Climate Change. 2010 to 2015 Government Policy: Greenhouse Gas Emissions. Available online: https:/ / www.gov.uk/government/publications/2010-to-2015-governmentpolicy-greenhouse-gas-emissions/2010-to-2015-government-policy-greenhouse-gas-emissions (accessed on 25 July 2017).

2. European Parliament Directive. 2010/31/EU of the European Parliament and of the Council of 19 May 2010 on the Energy Performance of Buildings. Off. J. Eur. Union 2010, 1, 1-16.

3. Carbon Trust. Closing the Gap_Lessons Learned on Realising the Potential of Low Carbon Building Design; Queen's Printer: London, UK, 2012. [CrossRef]

4. Bordass, B.; Cohen, R.; Field, J. Energy Performance of Non-Domestic Buildings: Closing the Credibility Gap. Presented at the Building Performance Congress, Frankfurt, Germany, 19-22 April 2004.

5. Bordass, B.; Cohen, R.; Standeven, M.; Leaman, A. Assessing building performance in use 3: Energy performance of the Probe buildings. Build. Res. Inf. 2001, 29, 114-128. [CrossRef]

6. Palmer, J.; Terry, N.; Armitage, P. Building Performance Evaluation Programme: Findings from Non-Domestic Projects; Innovate UK: Swindon, UK, 2016; 75p.

7. Royal Institute of British Architects; Chartered Institution of Building Services Engineers. CarbonBuzz: Evidence. Available online: http:/ / www.carbonbuzz.org/evidencetab.jsp (accessed on 25 July 2017).

8. Forman, T.; Mutschler, R.; Guthrie, P.; Soulti, E.; Pickering, B.; Byström, V; Lee, S.M. Improving Building Energy Performance in Universities: The Case Study of the University of Cambridge. In Handbook of Theory and Practice of Sustainable Development in Higher Education; Leal Filho, W., Brandli, L., Castro, P., Newman, J., Eds.; Springer International Publishing: Cham, Germany, 2017; Volume 1, pp. 245-266. 
9. Cohen, R.; Standeven, M.; Bordass, B.; Leaman, A. Assessing building performance in use 1: The Probe process. Build. Res. Inf. 2001, 29, 85-102. [CrossRef]

10. Menezes, A.C.; Cripps, A.; Bouchlaghem, D.; Buswell, R. Predicted vs. actual energy performance of non-domestic buildings: Using post-occupancy evaluation data to reduce the performance gap. Appl. Energy 2012, 97, 355-364. [CrossRef]

11. Woods, J. Department of Engineering Institute for Manufacturing Post Occupancy Evaluation. Unpublished work, 2011.

12. Way, M. University of Cambridge Estate Management and Building Services Soft Landings Workplan. Unpublished work, 2006.

13. Usable Buildings Trust; Bunn, R. The Soft Landings Core Principles; BSRIA: Bracknell, UK, 2014.

14. BIM Task Group. Government Soft Landings; Cabinet Office: London, UK, 2013.

15. Building Research Energy Conservation. Energy Consumption Guide 19-Energy Use in Offices; Chartered Institution of Building Services Engineers: London, UK, 2003; pp. 1-24.

16. Department of Energy and Climate Change. The Non-Domestic National Energy Efficiency Data Framework (ND-NEED); DECC: London, UK, 2014.

17. Field, J. CIBSE TM46:2008. Energy Benchmarks; The Chartered Institution of Building Services Engineers: London, UK, 2008.

18. Kelly, S.; Crawford-Brown, D.; Pollitt, M.G. Building performance evaluation and certification in the UK: Is SAP fit for purpose? Renew. Sustain. Energy Rev. 2012, 16, 6861-6878. [CrossRef]

19. Department for Communities and Local Government. Display Energy Certificates and Advisory Reports for Public Buildings; Department for Communities and Local Government: London, UK, 2015.

20. Cole, R.J.; Valdebenito, M.J. The importation of building environmental certification systems: International usages of BREEAM and LEED. Build. Res. Inf. 2013, 41, 662-676. [CrossRef]

21. Lee, W.L. Benchmarking energy use of building environmental assessment schemes. Energy Build. 2012, 45, 326-334. [CrossRef]

22. Tuohy, P.G.; Murphy, G.B. Are current design processes and policies delivering comfortable low carbon buildings? Archit. Sci. Rev. 2014, 58, 39-46. [CrossRef]

23. Parker, J. The Value of BREEAM; BSRIA: London, UK, 2012.

24. De Wilde, P. The gap between predicted and measured energy performance of buildings: A framework for investigation. Autom. Constr. 2014, 41, 40-49. [CrossRef]

25. Newsham, G.; Mancini, S.; Birt, B. Do LEED-certified buildings save energy? Yes, but ... Energy Build. 2009, 41, 897-905. [CrossRef]

26. Way, M.; Bordass, B. Making feedback and post-occupancy evaluation routine 2: Soft landings-Involving design and building teams in improving performance. Build. Res. Inf. 2005, 33, 353-360. [CrossRef]

27. Usable Buildings Trust; Way, M.; Bunn, R. The Soft Landings Framework—For Better Briefing, Design, Handover and Building Perfomance In-Use; BSRIA: London, UK, 2014.

28. Austin, B. The Performance Gap: Causes \& Solutions. Green Construction Board Buildings Working Group; ARUP: London, UK, 2013.

29. University of Cambridge Estate Management and Building Services. IfM Energy Key Performance Indicators; University of Cambridge: Cambridge, UK, 2013.

30. Norris, T. Bridging the Gap Between Designed and Real Consumption: What Can the University of Cambridge Teach Us about Energy Reporting and Monitoring? Bachelor's Thesis, University of Cambridge, Cambridge, UK, 2014, unpublished.

31. Bordass, B.; Leaman, A. Making feedback and post-occupancy evaluation routine 1: A portfolio of feedback techniques. Build. Res. Inf. 2005, 33, 347-352. [CrossRef]

32. University of Cambridge. The Design and Construction of Environmentally Sustainable New Buildings. Available online: http:/ / www.environment.admin.cam.ac.uk/resource-bank/guidance-documents/designand-construction-environmentally-sustainable-new-buildings\#heading1.0 (accessed on 25 July 2017).

33. Boyce, H. IfM Energy Performance Certificate 0510-0931-9300-2022-4006. Available online: https: / /www.ndepcregister.com/ReportDownload?rrn=0510-0931-9300-2022-4006\&repType=EPC\&lc= $1 \&$ source $=0$ \&lang $=$ en (accessed on 25 July 2017).

34. Passive House Institute. Passive House Database. Available online: http:/ /www.passivhausprojekte.de/ index.php (accessed on 25 July 2017). 
35. Feist, W. Certification as "Quality Approved Passive House" Criteria for Non-Residential Passive House Buildings; Passivhaus-Institut: Darmstadt, Germany, 2009.

36. Parker, N. A Comparison of Green Building Rating Systems: Living Building Challenge 2.0. In Proceedings of the Annual Conference of the Canadian Society for Civil Engineering, Edmonton, AB, Canada, 6-9 June 2012.

37. International Living Future Institute. Living Building Challenge 3.1 Standard. Available online: http:/ / living-future.org/lbc (accessed on 25 July 2017).

38. International Living Future Institute. Zero Energy Certification. Available online: https://living-future.org/ net-zero/certification/ (accessed on 25 July 2017).

39. Cheshire, D.; Menezes, A.C. Evaluating Operational Energy Performance of Buildings at the Design Stage; CIBSE TM54:2013; The Chartered Institution of Building Services Engineers London: London, UK, 2013; ISBN 978-1-906846-38-1.

40. Cohen, R. TSB BPE: Reporting Non Domestic Building Energy Performance after a TM22 Analysis; Innovate UK: Swindon, UK, 2013; pp. 1-8.

41. University of Cambridge Estate Management and Building Services. Carbon Management Plan 2010-2020; University of Cambridge: Cambridge, UK, 2010.

42. University of Cambridge Environment and Energy. Behavioural Change: Gurdon Institute. Available online: http:/ / www.environment.admin.cam.ac.uk/resource-bank/case-studies/case-studies-energy-andcarbon-reduction/behavioural-change-gurdon (accessed on 25 July 2017).

(C) 2017 by the authors. Licensee MDPI, Basel, Switzerland. This article is an open access article distributed under the terms and conditions of the Creative Commons Attribution (CC BY) license (http://creativecommons.org/licenses/by/4.0/). 